Document downloaded from:

http://hdl.handle.net/10251/150349

This paper must be cited as:

Wegrzyn, M.; Ortega, A.; Benedito, A.; Giménez Torres, E. (2015). Thermal and electrical conductivity of melt mixed polycarbonate hybrid composites co-filled with multi-walled carbon nanotubes and graphene nanoplatelets. Journal of Applied Polymer Science. 132(37):42536-1-42536-8. https://doi.org/10.1002/app.42536

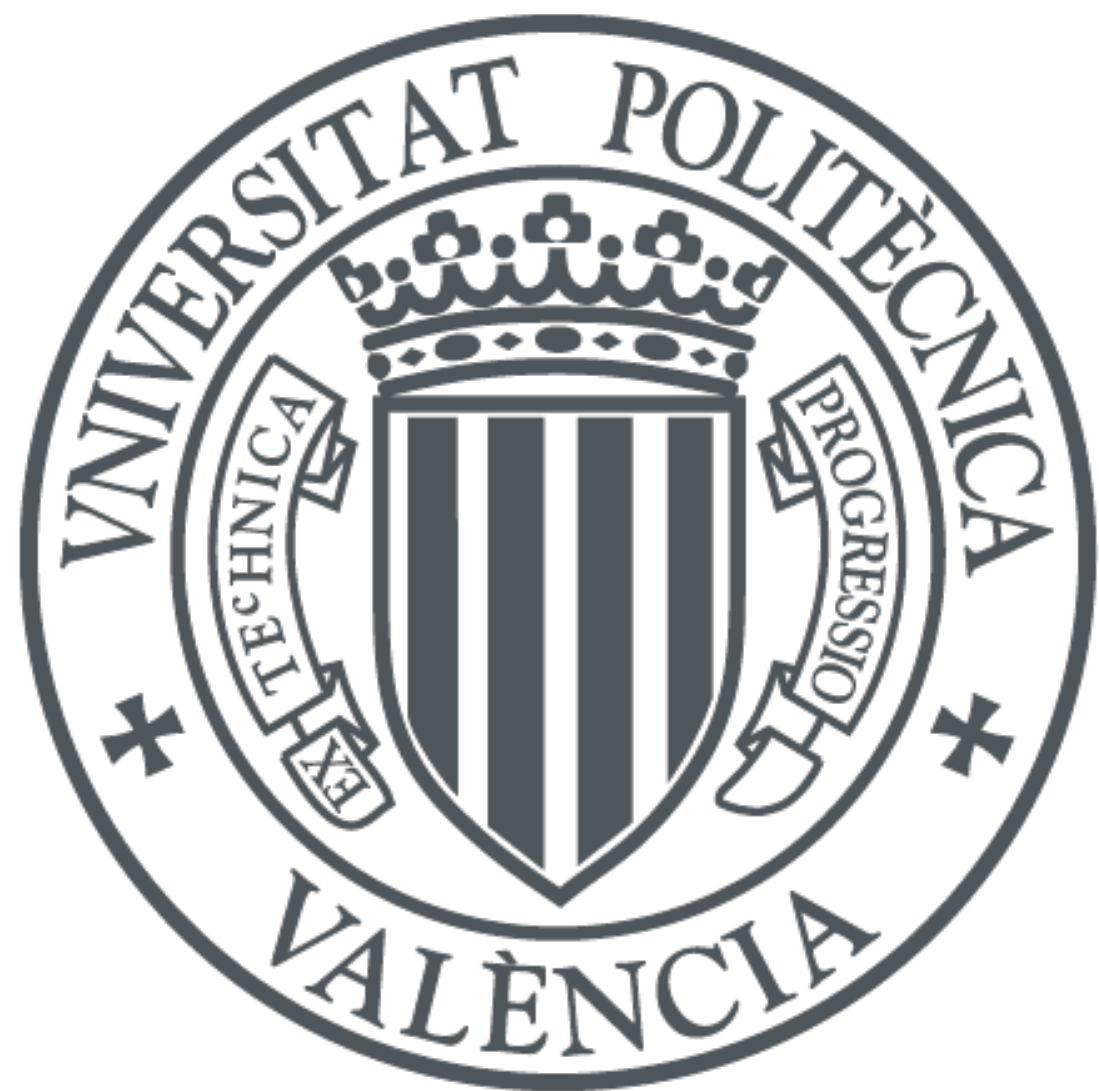

The final publication is available at

https://doi.org/10.1002/app.42536

Copyright John Wiley \& Sons

Additional Information

"This is the peer reviewed version of the following article: Wegrzyn, M., Ortega, A., Benedito, A., \& Gimenez, E. (2015). Thermal and electrical conductivity of melt mixed polycarbonate hybrid composites co\&\#8208;filled with multi\&\#8208;walled carbon nanotubes and graphene nanoplatelets. Journal of Applied Polymer Science, 132(37), which has been published in final form at https://doi.org/10.1002/app.42536. This article may be used for non-commercial purposes in accordance with Wiley Terms and Conditions for Self-Archiving." 


\section{Applied Polymer}

Thermal and electrical conductivity of melt mixed polycarbonate hybrid composites co-filled with multi-walled carbon nanotubes and graphene nanoplatelets.

\begin{tabular}{|r|l|}
\hline Journal: & Journal of Applied Polymer Science \\
\hline Manuscript ID: & APP-2015-01-0337 \\
\hline Wiley - Manuscript type: & Review \\
\hline Keywords: & $\begin{array}{l}\text { composites, mechanical properties, nanotubes, graphene and fullerenes, } \\
\text { thermal properties }\end{array}$ \\
\hline
\end{tabular}

SCHOLARONE ${ }^{\text {m }}$

Manuscripts 


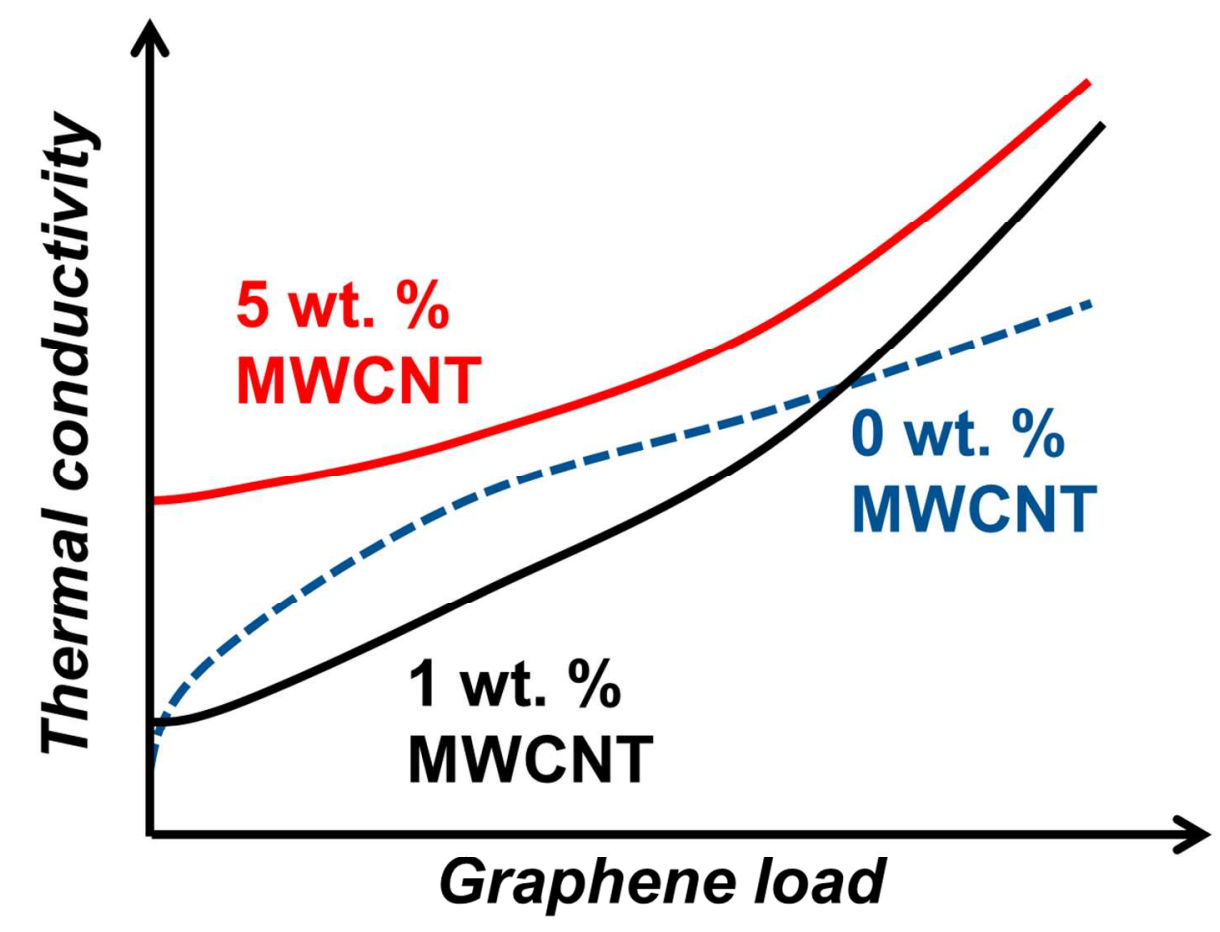

Graphical abstract

$228 \times 178 \mathrm{~mm}(150 \times 150 \mathrm{DPI})$

John Wiley \& Sons, Inc. 


\title{
Thermal and electrical conductivity of melt mixed polycarbonate hybrid composites co-filled with multi-walled carbon nanotubes and graphene nanoplatelets.
}

\author{
Marcin Wegrzyn $^{a *}$, Amaya Ortega $^{a}$, Adolfo Benedito $^{a}$, Enrique Gimenez $^{b}$ \\ ${ }^{a}$ Instituto Tecnológico del Plástico (AIMPLAS), Calle Gustave Eiffel 4, 46980 Paterna, Spain \\ ${ }^{b}$ Instituto de Tecnología de Materiales. Universidad Politécnica de Valencia, Camino de Vera, 46022 \\ Valencia, Spain \\ Correspondence: e-mail: marcinwegrzyn@hotmail.com
}

\section{ABSTRACT}

In this work, we present thermoplastic nanocomposites of polycarbonate (PC) matrix with hybrid nanofillers system formed by a melt-mixing approach. Various concentrations of multi-wall carbon nanotubes (MWCNT) and graphene nanoplatelets (GnP) were mixed in to polycarbonate and the melt was homogenized. The nanocomposites were compression molded and characterized by different techniques. Torque dependence on the nanofiller composition increased with the presence of carbon nanotubes. The synergy of carbon nanotubes and graphene nanoplatelets showed exponential increase of thermal conductivity, which was compared to logarithmic increase for nanocomposite with no MWCNT. Decrease of Shore A hardness at elevated loads present for all investigated nanocomposites was correlated with the expected low homogeneity caused by a low shear during melt-mixing. Mathematical model was used to calculate elastic modulus from Shore A tests results. Vicat softening temperature showed opposite pattern for hybrid nanocomposites and for PC-MWCNT increasing in the latter case. Electrical conductivity boost was explained by the collective effect of high nanofiller loads and synergy of MWCNT and GnP.

\section{INTRODUCTION}

Thermoplastic polymer composites filled with carbon-based nanomaterials offer many solutions for material science. ${ }^{1}$ Significant improvement of electrical and thermal properties of insulating polymers in these nanocomposites is attributed to the carbon nanotubes or graphene nanoplatelets used as filler. ${ }^{2,3} \mathrm{~A}$ unique structure of these nanofillers provides also good mechanical performance of nanocomposites. ${ }^{4,5}$ These two aforementioned 
nanomaterials, often used separately as fillers, ${ }^{6,7}$ recently gained more attention as components of a hybrid systems-based nanocomposites. ${ }^{8,9}$ Complex engineering materials formed by co-filling thermoplastics with one- and two-dimensional fillers provide a broad range of opportunities for science and technology. However, a good quality interconnected network of nanofillers is necessary to reach the desired improvement of properties. The main problem distracting the performance of MWCNT and GnP is inefficient energy applied during processing disabling the breakage of nanofiller macrostructures causing inhomogeneous morphology of the final nanocomposite. ${ }^{10}$ This is related to the breakage of primary carbon nanotube agglomerates in the process of macrostructure penetration by polymer melt ${ }^{11}$ or graphite exfoliation in order to obtain monolayer sheets of graphene nanoplatelets. ${ }^{12}$ In a common nanocomposite formation by melt-mixing the energy input is usually controlled by the parameter: specific mechanical energy (SME). ${ }^{13}$ Nevertheless, SME is convenient mainly for a continuous process and can be replaced in parameters influence analysis by torque. This is a desired solution when an internal mixer is used instead of a twinscrew extruder or when high nanofiller loads are used disabling microscopic methods of morphology determination. ${ }^{14}$

Intrinsic thermal conductivity of polymer-based materials is a key feature for processing and for application. ${ }^{15}$ Exfoliated or expanded graphene is reported to give good results improving the thermal conductivity of thermoplastic materials. The performance depends on the aspect ratio of the individual particles ${ }^{16}$ and the dispersion quality in the matrix. ${ }^{17}$ However, often high volume fractions of nanofillers are necessary for the desired increase of thermal conductivity which restricts some of the commonly used processing methods such as extrusion or injection molding. ${ }^{18}$ Therefore, hybrid nanocomposites are the optimal solution to decrease filling load with maintaining comparable thermal properties. ${ }^{19}$ Hybrid 
fillers additionally induce morphological changes in the matrix (e.g. chains alignment) which has a positive effect on the thermal conductivity. ${ }^{20} \mathrm{~A}$ reported synergistic effect of carbon nanotubes and graphene in epoxy matrix show greater increase of thermal conductivity and mechanical properties for co-filled nanocomposites than for nanocomposites individually filled with each of these nanofillers. ${ }^{21}$ Besides, Vicat hardness as a parameter defining polymer softening point is improved with carbon nanotubes content which is reported for commodity polymers like PP obtained by a twin-screw extrusion. ${ }^{22}$ However, the balance of properties occurs at low loads (1-3 wt. \%) which suggests the occurrence of percolation threshold. Opposite observations reported for non-carbonous fillers show a decreasing Vicat softening point with an increase of volume fraction. ${ }^{23}$ Shore $A$ hardness showing the values measured at room temperature increases with carbon nanotubes ${ }^{24}$ and with twodimensional silicate ${ }^{25}$ concentration increase. Nevertheless, the change observed was clearly higher for the hybrid system combining these nanofillers. A correlation between the elastic modulus in compression and Shore A hardness was reported with a mathematical simulation of experimental data giving an acceptable agreement with ca. $5 \%$ error. ${ }^{26}$ Thus, the theory of Boussinesq for comparison of both data sets is adequate. Furthermore, no modification of Shore A method in order to correlate the data with elastic modulus ${ }^{27}$ was necessary. The aforementioned reports confirm that the dependence of mechanical performance on the various one- and two-dimensional fillers in a hybrid system exists. This is reported especially for the low-to-moderate filler concentrations.

In this work, we present PC-MWCNT/GnP nanocomposites prepared by melt-mixing in an internal mixer. Various nanofiller content and mutual nanofillers ratio allow studying the influence of synergistic effect on thermal and electrical conductivity. The study of torque during the nanocomposites formation shows the influence of nanofillers composition. 
Thermal conductivity and thermal effusivity were determined on a compression molded specimens with a Modified Transient Plane Source (MTPS) approach. Hardness measured at room temperature (Shore A) and Vicat hardness were determined in order to observe the influence of carbon nanotubes and graphene nanoplatelets in hybrid system. A simple mathematical model was used in order to calculate the elastic modulus in compression from Shore A test data. Electrical conductivity measured with a two-point contact method is given in order to correlate electrical and thermal performance of the nanocomposites.

\section{EXPERIMENTAL}

\section{- Materials}

Commercial polycarbonate (PC) Lexan ELX 6013 (MVR 5 g/10min) was supplied by SABIC Innovative Plastics. Multi-walled carbon nanotubes (MWCNT) NC7000 with average diameter $9.5 \mathrm{~nm}$ and average length $1.5 \mu \mathrm{m}$ were supplied by Nanocyl. Graphene nanoplatelets $(\mathrm{GnP}) \times \mathrm{GnP}-\mathrm{M} 5$ with thickness $6-8 \mathrm{~nm}$ and average particle diameter $5 \mu \mathrm{m}$ were supplied by XG Sciences.

\section{- Preparation of nanocomposites}

Nanocomposites with various nanofillers concentrations shown in Table 1 were prepared on a Brabender Plasti-Corder PL-2000 internal mixer at screw speed $120 \mathrm{rpm}$ and barrel temperature $280^{\circ} \mathrm{C}$. Polycarbonate (PC) was introduced to the mixing chamber and blended for 1 min until the torque was constant. Carbon nanotubes (MWCNT) and graphene nanoplatelets $(\mathrm{GnP})$ were added to melted polycarbonate $(\mathrm{PC})$ after this time and such 
formed nanocomposite was mixed for 9 minutes. PC-MWCNT/GnP nanocomposites subtracted from the mixing cavity were compression molded at $280^{\circ} \mathrm{C}$ on a Collin 6300 hydraulic press into the rectangular specimens with dimensions $25 \times 25 \times 5 \mathrm{~mm}^{3}$. A $25 \mathrm{~min}$ compression process was composed of five-steps with applied pressures varied between 5 bar and 140 bar.

\section{- Characterization}

The tests were carried out on the compression molded specimens. Thermal conductivity of the nanocomposites was measured on a TCi TH89 Modified Transient Plane Source (MTPS) thermal conductivity analyzer (C-Therm Technologies). A one-sided heat reflectance sensor shown in Figure 1a provides a controlled amount of heat changing the temperature of a sample surface inducing the voltage drop. Two measurements (Figure 1b) were carried out for each of the five rectangular specimens at ambient temperature $\left(26.1 \pm 0.5^{\circ} \mathrm{C}\right)$ with deionized water used as a contact medium. Individual test included data collection step of $0.8 \mathrm{~s}$ and sensor cooling step between the data acquisition of $60 \mathrm{~s}$.

Hardness of the nanocomposites was measured on an A-type Shore durometer. In this method a standardized intender was pressed by $8.064 \mathrm{~N}$ force into the specimen for $15 \mathrm{~s}$ at ambient temperature. After this time the hardness was determined based on the depth of indentation. Mathematical model was introduced in order to calculate the Elastic modulus from the hardness data. 
Vicat softening point was determined with B50 method following the EN ISO 306 standard. In this method a flat-ended needle was constantly pressed by $50 \mathrm{~N}$ force into the specimen. Temperature of silicon oil used as a medium was raised from ambient with a rate $50{ }^{\circ} \mathrm{Ch}^{-1}$.

Electrical resistivity was measured by a two-point contact configuration on a Keithley 2000 Multimeter source/meter. Silver electrodes were painted on the samples in order to improve contact between the specimen and the measuring electrodes.

\section{RESULTS AND DISCUSSION}

Each of the hybrid nanocomposites filled with carbon nanotubes (MWCNT) and graphene nanoplatelets $(\mathrm{GnP})$ prepared with a single, ten minutes-long processing step shows a decrease of torque with the homogenization of the melt (Figure 2 and Table 2). The curves in Figure 2 represent torque during the formation of selected PC-GnP nanocomposites with no carbon nanotubes. A clear increase of torque representing the melt resistance to deformation during mixing increases with the nanofiller load until $10.0 \mathrm{wt}$. \% GnP. A change of nanocomposite behavior for material 0T/15G is explained by the lubricating properties of graphite, stronger at elevated loads. A 10.0 wt. \% GnP seems to be the limit above which the agglomerates are large enough to disable strong nano-scale interactions between graphene and polymer chains. Besides, intensification of the lubricating properties of graphene ${ }^{28}$ at elevated loads facilitates the laminar flow of polymer melt in discrete layers. ${ }^{29}$ Furthermore, the torque seems to be more constant above the $8^{\text {th }}$ minute of processing $\left(7^{\text {th }}\right.$ minute of the nanocomposite mixing) for each investigated GnP concentration present in Figure 2. This reduction of the curve slope indicates the point of the formation of a relatively homogeneous nanocomposite. No significant improvement is expected with the increase of 
mixing time at the applied conditions, as from this moment the degradation of polymer matrix causing polymer chains shortening competes with the improvement of the nanofiller dispersion. On the contrary, the torque observed for polycarbonate decreases consecutively with the processing time and no plateau occurs, suggesting the influence of a slight polymer degradation caused by the temperature and the shear.

Further increase of torque is observed when carbon nanotubes are introduced to the system together with graphene (Table 2). During each individual process the torque behaves similarly to PC-GnP and an increase with nanofillers load is observed. Besides, the plateau observed for PC-GnP started at the $8^{\text {th }}$ minute of processing does not occur when carbon nanotubes are introduced. Such an effect is most probably related to inhomogeneous nanofillers dispersion after this processing time. Therefore, the processing time for hybrid nanocomposites formation in internal mixer should be balanced providing good dispersion of nanofillers and the lowest possible matrix degradation. Data present in Table 2 shows much stronger increase of torque between 1T/1G and 1T/0G than for the further increase of GnP content. A ca. $13 \%$ torque increase is observed when $1.0 \mathrm{wt}$. \% GnP is introduced to the PC-GnP (creating 1T/1G) and $8 \%$ increase for the 5.0 wt. \% GnP (1T/5G) and 10.0 wt. \% GnP (1T/10G). This observation is confirmed also for the nanocomposites with $5.0 \mathrm{wt}$. \% MWCNT but the increase of torque is minor. Such an effect is related mainly to the type of nanofiller. Addition of graphene nanoplatelets causes the formation of interconnected hybrid network increasing the viscosity of the nanocomposite. Besides, nanocomposites with the total nanofiller loads between $1.0 \mathrm{wt} . \%$ and $2.0 \mathrm{wt} . \%$ are most likely in the range of mechanical percolation, which should show the observed effect on torque. Similarly to the materials with no carbon nanotubes shown in Figure 2, the lower values of torque were observed for 
nanocomposites $1 \mathrm{~T} / 15 \mathrm{G}$ than for $1 \mathrm{~T} / 10 \mathrm{G}$. This is understood as a strong impact of the high load of graphene nanoplatelets.

Besides, the nanocomposite 0T/1G (Figure 2) shows higher torque value than 1T/0G (Table 2). The difference of $c a .6 \%$ observed above the $6^{\text {th }}$ minute of processing indicates that at the low nanofiller loads the nanocomposite filled with graphene causes more obstacles for the mixer. This may be caused by the better dispersion and thus stronger interactions between the nanomaterial and polymer chains. Nevertheless, at low loads the penetration of carbon nanotube agglomerates by polymer melt leading to the individually-dispersed nanoparticles seems to be easier than a good dispersion of graphene nanoplatelets including the previous exfoliation. Reports show improved dispersion ability of nanomaterials in some hybrid systems. ${ }^{30,31}$ A relatively low shear rate during the nanocomposites preparation suggests a non-efficient MWCNT agglomerates breakage and the formation of incomplete network in polymer matrix. Opposite effect with the synergy between carbon nanotubes and graphene nanoplatelets is observed in nanocomposites with the high total nanofiller load (6.0 wt. \%): 1T/5G and 5G/1T. Summarizing, the torque increases with an increase of MWCNT load and a decrease of GnP load. Material behavior changes at high nanofiller concentration so the efficiency of graphene nanoplatelets dispersion in polymer matrix is reduced. $^{32}$

Thermal conductivity measured by the Modified Transient Plane Source (MTPS) approach

(Figure 1) increases with the total nanofiller load for all investigated nanocomposites (Figure 3). The expected higher values for the hybrid compositions containing $5.0 \mathrm{wt}$. \% MWCNT were observed along the whole series. The curves recorded for the hybrid nanocomposites follow an exponential function while the curve obtained for the PC-GnP is logarithmic. For 
the hybrid nanocomposites with 1.0 wt. \% MWCNT thermal conductivity is generally lower than for the PC filled only with graphene nanoplatelets. This is attributed to the aforementioned synergy causing the decrease of torque for $1 \mathrm{~T} / 5 \mathrm{G}$ comparing to $5 \mathrm{~T} / 1 \mathrm{G}$ (Table 2), having origins in the dispersion ability of one nanomaterial with the presence of another. Besides, the alignment of nanofiller is reported to play a key role in thermal conductivity performance of nanocomposites. ${ }^{33}$ Such behavior is expected to change at high loads and for the material $1 \mathrm{~T} / 15 \mathrm{G}$ thermal conductivity is higher than for the $0 \mathrm{~T} / 15 \mathrm{G}$. The effect of the increase of thermal conductivity at such high NgP load with the presence of 1.0 wt. \% MWCNT is probably related to the amount rather than the type of nanofiller.

A parameter $\mathrm{K}_{\mathrm{nc}} / \mathrm{K}_{\mathrm{mx}}$ often used to represent the efficiency of material treatment on thermal properties is a ratio between the obtained thermal conductivity $\left(\mathrm{K}_{\mathrm{nc}}\right)$ and thermal conductivity of a neat matrix $\left(\mathrm{K}_{\mathrm{mx}}\right)$, a $0.261 \mathrm{WmK}^{-1}$ for polycarbonate. Value generally increases with the increase of MWCNT and GnP load. Thus, regarding the highest studied graphene nanoplatelets load of 15.0 wt. \%, the $K_{n c} / K_{m x}$ gives values between $2.79(0 T / 15 G)$ and $3.33(5 \mathrm{~T} / 15 \mathrm{G})$. For significantly lower $\mathrm{GnP}$ concentration $1.0 \mathrm{wt} . \%, \mathrm{~K}_{\mathrm{nc}} / \mathrm{K}_{\mathrm{mx}}$ is between $1.23(0 T / 1 G)$ and $1.83(5 T / 1 G)$. This behavior is confronted with the PC-MWCNT nanocomposite without graphene nanoplatelets and no significant change is observed for 1.0 wt. \% MWCNT before and after the addition of $\mathrm{GnP}(1 \mathrm{~T} / 0 \mathrm{G}$ and $1 \mathrm{~T} / 1 \mathrm{G}$, respectively). This confirms the importance of the hybrid nanofiller system at high concentrations in order to boost the thermal conductivity of insulating polymer matrix.

Thermal effusivity of nanocomposites $e_{n c}$ defined by Equation 1 is present in Table 3 . The values agree with the previous observations of thermal conductivity performance. The ability of the nanocomposite to absorb/exchange heat depends on the thermal conductivity of this 
nanocomposite $K_{n c}$, its density $\rho_{n c}$ and the specific heat capacity $c_{p}$. A nearly linear increase of the thermal effusivity with an increase of graphene nanoplatelets content is observed for the nanocomposites with no carbon nanotubes. Introduction of MWCNT and the formation of hybrid nanocomposites results with the exponential increase of effusivity with the increase of GnP load. Such a non-linear dependence is related to the presence of MWCNTGnP interconnected network where a synergy of the hybrid nanofiller system increases the possible number of contacts between the particles. From a defined concentration the thermal performance changes significantly with a slight increase of the load. At $15.0 \mathrm{wt}$ \% GnP (1T/15G and 5T/15G) the thermal effusivity is almost equal for both nanocomposites, showing only $16.3 \%$ difference. This agrees with the aforementioned statement regarding upper level of the efficient nanofiller load.

$e_{n c}=\left(K \rho_{n c} c_{p}\right)^{1 / 2}$

Hardness of the nanocomposites measured by a Shore type A method is shown in Figure 4. An initial improvement of hardness is observed with the introduction of $1.0 \mathrm{wt}$. \% GnP, for materials $0 \mathrm{~T} / 1 \mathrm{G}$ and $1 \mathrm{~T} / 1 \mathrm{G}$. The value between these nanocomposites does not differ significantly due to the effect of low nanofiller load. ${ }^{34}$ Further development of the nanocomposites show that hardness decreases significantly, below the value recorded for the neat polycarbonate. Further increase of the total nanofiller load for both series shown in Figure 4 indicated the relative similarity between the material with $0.0 \mathrm{wt}$. \% MWCNT and the material with $5.0 \mathrm{wt}$ \% MWCNT occurs at low (1.0 wt. \%) and high (15.0 wt. \%) GnP 
concentrations. Nevertheless, the values are clearly lower for PC-GnP than for the hybrid nanocomposite with $1.0 \mathrm{wt}$. \% MWCNT which confirms the aforementioned synergy. Besides, literature reports show the optimal size of grains in polymer matrix $d_{c}=10 \mathrm{~nm}$ providing the highest hardness. ${ }^{35}$ The decrease of hardness below and above that defined grain size is correlated with the inter-granular processes. This theory can be adapted to the nanocomposites where a well-dispersed nanofiller phase meets the $d_{c}$ requirement. ${ }^{36}$ Thus, it seems that the concentration of macrostructures (micro-scale agglomerates) in the studied polycarbonate nanocomposites at GnP loads above $5.0 \mathrm{wt} . \%$ is relatively high. Therefore, the explanation of the decrease of Shore A hardness can be related to the inhomogeneity of the material at elevated nanofiller loads. ${ }^{37}$ However, at such high concentrations of carbon nanomaterials the transparency of the nanocomposite disables any statistically-supported analyses of micrographs revealing the quality of the morphology.

Modulus of elasticity in compression present in Table 4 is determined basing on a Shore $A$ hardness results. ${ }^{26}$ Equation 2 defining the relationship between these parameters ( $E$ and $S h_{A}$, respectively) includes the normalized radius of the indenter $R=0.395 \mathrm{~mm}$, Poisson's ratio $\mu=0.5$ and constants related to the relation between the depth of penetration and the Shore A hardness: $C_{1}=0.549 \mathrm{~N}, C_{2}=0.07516 \mathrm{~N}$ and $C_{3}=0.025 \mathrm{~mm}$. A standard deviation between the mathematical model and the experimental data is $5.4 \% .{ }^{26}$ Results of calculation show an increase (ca. $2.5 \%$ ) of polycarbonate elastic modulus in compression after the formation of 0T/1G and 1T/1G. This initial increase of elastic modulus, analogous to the Shore A hardness, is followed by a significant decrease at elevated total nanofiller loads. A clear reduction of $E$ is calculated with relatively high accuracy and can be related to the size of filler agglomerates. At elevated loads both nanofillers tend to exist in nanocomposites in the form of macrostructures, which causes a decrease of mechanical properties of the final material. 
$E=\frac{1-\mu^{2}}{2 \cdot R \cdot C_{3}} \cdot \frac{C_{1}+C_{2} \cdot S h_{A}}{100-S h_{A}} \cdot\left(2.6-0.02 \cdot S h_{A}\right)$

Figure 5 with the Vicat softening temperature (VST) of the selected nanocomposites shows a behavior strongly dependent on the presence of carbon nanotubes. Literature reports confirm an increase of the softening temperature with the increase of carbon nanotube or the other co-filler content. ${ }^{22,38}$ This behavior is also observed for the hybrid PC-MWCNT/GnP nanocomposites at 1.0 wt. \% MWCNT and 1.0 wt. \% GnP (1T/1G). An optimal load below 3.0 wt. \% nanofller is reported to show the best Vicat temperature improvement for various nanofillers, which is in agreement with the findings present here. ${ }^{22,38}$ Further increase of graphene nanoplatelets concentration with the presence of $1.0 \mathrm{wt} . \%$ carbon nanotubes causes the decrease of softening temperature. This behavior is opposite when no MWCNT is present in the matrix, which confirms stronger impact of graphene on VST due to a plate-like structure. Besides, the low value of VST is observed for $1 \mathrm{~T} / 10 \mathrm{G}$ and $1 \mathrm{~T} / 15 \mathrm{G}$ is similar and higher than a VST for 1T/0G. It seems that the aforementioned optimal load should be also selected for hybrid nanocomposites and a synergistic effect needs to be considered.

Electrical conductivity values of the hybrid PC-based nanocomposites measured by a twopoint method described elsewhere ${ }^{39}$ are shown in in Figure 6 and in Table 5. The improvement of electrical properties of PC/GnP in Table 5 shows the performance of a 4 orders of magnitude increase of the virgin polycarbonate value for $1.0 \mathrm{wt}$. \% GnP (0T/1G). Besides, a significant improvement of electrical conductivity with graphene nanoplatelets concentration occurs for both studied carbon nanotube loads (Figure 6). A $33.2 \%$ increase 
between $1 T / 0 G$ and $1 T / 15 G$ or a $167.0 \%$ increase between $5 T / 0 G$ and $5 T / 15 G$ shows the possible performance of the studied hybrid nanofiller system. Furthermore, a difference between the nanofillers is clear when the electrical conductivity performance for the same concentration is compared. The $0 \mathrm{~T} / 1 \mathrm{G}$ shows an increase of a ca. $10^{4} \mathrm{Scm}^{-1}$ of the PC value, while the $1 \mathrm{~T} / 0 \mathrm{G}$ gives $10^{13} \mathrm{Scm}^{-1}$. Nevertheless, the effect of a hybrid system does not show significant difference favoring one nanofiller or another. Nanocomposite $1 \mathrm{~T} / 5 \mathrm{G}$ shows $1.0 \mathrm{E}-$ $01 \mathrm{Scm}^{-1}$ while 5T/1G: 4.1E-01 Scm${ }^{-1}$. Such a boost observed for PC-MWCNT/GnP is attributed to a collective effect of high total nanofillers load and to the formation of interconnected hybrid network including two different types of nanofiller: one-dimensional nanotubes and two-dimensional flakes. Furthermore, a rather low shear during the whole processing does not affects the length of carbon nanotubes which is beneficial for the formation of the interconnected nanofillers network. Shortening of carbon nanotubes is reported to distract significant improvement of carbon nanotubes-based nanocomposites. ${ }^{37}$

\section{CONCLUSIONS}

Polycarbonate-based nanocomposites with a hybrid nanofillers system including multi-wall carbon nanotubes (MWCNT) and graphene nanoplatelets (GnP) show improvement of thermal and electrical conductivity of the virgin matrix. The nanocomposites with moderateto-high loads of GnP provide significantly lower torque during melt mixing than the nanocomposites containing also MWCNT. Such effect was attributed to the synergy between nanoparticles resulting in the formation of interconnected hybrid network that increases viscosity and hampers screws rotation. Exponential boost of the thermal conductivity was explained with similar effect giving a $0.869 \mathrm{WmK}^{-1}$ for hybrid PC nanocomposite with 15.0 wt. 
$\% \mathrm{GnP}$ and 5.0 wt. \% MWCNT and $0.728 \mathrm{WmK}^{-1}$ with the absence of carbon nanotubes. This is an increase of polycarbonate value on the level of $233 \%$ and $180 \%$, respectively. Hardness obtained in a Shore A test, used also to determine elastic modulus in compression, decreased at elevated nanofiller concentrations even though an increase of the matrix value was recorded below the total nanofiller load of $5.0 \mathrm{wt}$. \%. Observation of the reduction of Vicat softening temperature for hybrid nanocomposites and the increase for PC-MWCNT is related with the insufficient shear provided during the formation of nanocomposite causing limited ability of agglomerates breakage and graphene exfoliation. A correct mutual concentration of nanofillers should be selected in order to achieve highest values of the studied parameters. Electrical conductivity boost was observed to be dependent on the presence of carbon nanotubes and showed the collective effect of high nanofiller loads and synergy between carbon nanotubes and graphene nanoplatelets.

\section{ACKNOWLEDGEMENTS}

This work is funded by the European Community's Seventh Framework Program (FP7PEOPLE-ITN-2008) within the CONTACT project Marie Curie Fellowship under grant number 238363.

\section{REFERENCES}

[1] Su, I.; Schlögl, R. Chem. Sus. Chem. 2010, 3, 136-168.

[2] Yang, L.; Liu, F.; Xia, H.; Qian, X.; Shen, K.; Zhang, J. Carbon 2011, 49, 3274-3283.

[3] Singh, I.V.; Tanaka, M.; Endo M. Int. J. Therm. Sci. 2007, 46, 842-847. 
[4] Kuan, H.C.; Ma, C.C.M.; Chang, W.P.; Yuen, S.M.; Wu, H.H.; Lee, T.M. Comp. Sci. Tech. 2005, 65, 1703-1710.

[5] Arasteh, R.; Omidi, M.; Rousta, A.H.A.; Kazerooni, H. J. Macromol. Sci. B 2011, 50, 2464-2480.

[6] Wegrzyn, M.; Benedito, A.; Gimenez, E. J. Appl. Polym. Sci. 2014, 131, 40271-40279.

[7] Cai, D.; Jin, J.; Yusoh, K.; Rafiq, R.; Song, M. Compos. Sci. Technol. 2012, 72, 702-707.

[8] Martin-Gallego, M.; Verdejo, R.; Khayet, M.; Ortiz de Zarate, J.M.; Essalhi, M.; Lopez-Manchado, M.A. Nanoscale Res. Lett. 2011, 610, 1-7.

[9] Yu, D.; Dai, L. J. Phys. Chem. Lett. 2010, 1, 467-470.

[10] Haslam, M.D.; Raeymaekers, B. Comp. B 2013, 55, 16-21.

[11] Pötschke, P.; Dudkin, S.M.; Alig, I. Polymer 2003, 44, 5023-5030.

[12] Stankovich, S.; Dikin, D.A.; Dommett, G.H.; Kohlhaas, K.M.; Zimney, E.J.; Stach, E.A.; Piner, R.D.; Nguyen, S.T.; Ruoff, R.S. Nature 2006, 442, 282-286.

[13] Sathyanarayana, S.; Olowojoba, G.; Weiss, P.; Calgar, B.; Pataki, B.; Mikonsaari, I.; Huebner, C.; Hening, F. Macromol. Mater. Eng. 2013, 298, 89-105.

[14] Ye, L.; Wu, Q.; Qu, B. Polym. Degrad. Stabil. 2009, 94, 751-756.

[15] Ebadi-Dehaghani, H.; Nazempour, M. In Smart Nanoparticles Technology - Thermal Conductivity of Nanoparticles Filled Polymers; Hashim, A., Eds.; InTech, 2012, pp. 519-540.

[16] Kalaitzidou, K.; Fukushima, H.; Drzal, L. Carbon 2007, 45, 1446-1452.

[17] Mu, Q.; Feng, S.; Diao, G. Polym. Compos. 2007, 28, 125-130.

[18] King, J.A.; Barton, R.L.; Hauser, R.A.; Keith, J.M. Polym. Compos. 2008, 29, 421-428. 
[19] Hwang, Y.; Kim, M.; Kim, J. Compos Part. A - Appl. S. 2013, 55, 195-202.

[20] Babaei, H.; Keblinski, P.; Khodadadi, J.M. Inter. J. Heat Mass Tran. 2013, 58, 209-216.

[21] Yang, S.Y.; Lin, W.N.; Huang, Y.L.; Tien, H.W.; Wang, J.Y.; Ma, C.C.M.; Li, S.M.; Wang, Y.S. Carbon 2011, 49, 793-803.

[22] Pascual, J.; Peris, F.; Boronat, T.; Fenollar, O.; Balart, R. Polym. Eng. Sci. 2012, 733-740.

[23] Yasin, T.; Nisar, M.; Shafiq, M.; Nho, Y.C.; Ahmad, R.C. Polym. Compos. 2013, 34, 408-416.

[24] Zhang, W.D.; Shen, L.; Phang, I.Y.; Liu, T. Macromolecules 2004, 37, 256-259.

[25] Zhang, C.; Tjiu, W.W.; Liu, T.; Lui, W.Y.; Phang, I.Y.; Zhang, W.D. J. Psych. Chem. B 2011, 115, 3392-3399.

[26] Kunz, J.; Studer, M. Kunstst. Int. 2006, 6, 92-94.

[27] Sponagel, S.; Unger, J.; Spies, K.H. Kaut. Gummi Kunstst. 2003, 56, 608-613.

[28] Lin, J.; Wang, L.; Chen, G. Tribol. Lett. 2011, 41, 209-215.

[29] Wagner, J.R.; Mount, E.M.; Giles, H.F. In The Definitive Processing Guide and Handbook. Extrusion - Polymer Selection for Coextrusion; Giles, H.F.; Wagner, J.R.; Mount E.M., Eds.; Elsevier, Oxford, 2014, pp. 477-488.

[30] Qiu, L.; Yang, X.; Gou, X.; Yang, W.; Ma, Z.F.; Wallace, G.G.; Li, D. Chem. Eur. J. 2010, 16, 1065310658.

[31] Tian, L.; Meziani, M.J.; Lu, F.; Kong, C.Y.; Cao, L.; Thorne, T.J.; Sun, Y.P. Appl. Mater. Interfaces 2010, 2, 3217-3222.

[32] Potts, J.; Dreyer, D.R.; Bielawski, C.W.; Ruoff, R.S. Polymer 2011, 52, 5-25.

[33] Huang, H.; Liu, C.H.; Wu, Y.; Fan, S. Adv. Mater. 2005, 17, 1652-1656. 
[34] Shokrieh, M.M.; Hosseinkhani, M.R.; Naimi-Jamal, M.R.; Tourani, H. Polym. Test. 2013, 32, 45-51.

[35] Musil, J. In Nanostructured Hard Coatings - Physical and mechanical properties of hard nanocomposite films prepared by reactive magnetron sputtering; Cavaleiro, A.; De Hosson, J.T.M. Eds.; Kluwer Academic/Plenum Publishers, New York, 2006, pp. 407-463.

[36] J. Schiøtz, Simulations of nanocrystalline metals at the atomic scale. What can we do? What can we trust?, Proceedings of the $22^{\text {nd }}$ Ris International Symposium on Materials Science (2001) 127-139.

[37] T.K. Gupta, B.P. Singh, R.B. Mathur, S.R. Dhakate, Multi-walled carbon nanotube-graphenepolyaniline multiphase nanocomposite with superior electromagnetic shielding effectiveness, Nanoscale 6 (2014) 842-851.

[38] Pan, M.; Shi, X.; Li, X.; Hu, H.; Zhang, L. J. Appl. Polym. Sci. 2004, 94, 277-286.

[39] Wegrzyn, M.; Juan, S.; Benedito, A.; Gimenez, E. J. Appl. Polym. Sci. 2013, 130, 2152-2158. 

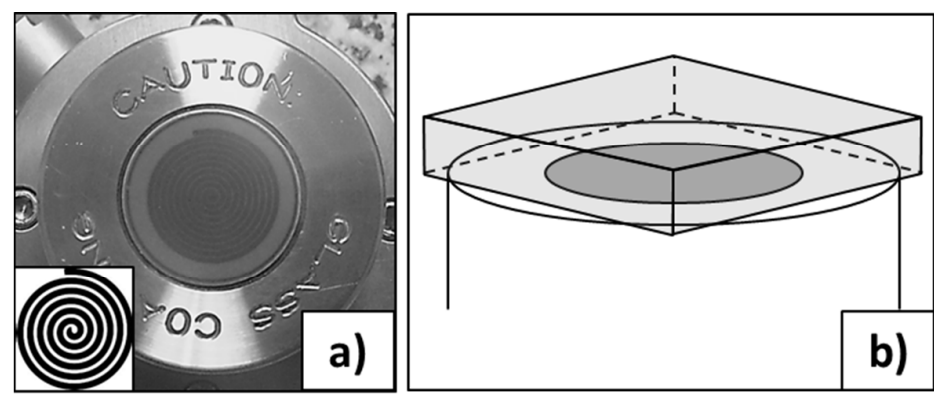

FIGURE 1: Methodology of thermal conductivity determination in hybrid PC-MWCNT/GnP nanocomposites: a) top-view on the sensor with a pictogram showing the sensor outlay, b) sample (gray) position on the sensor during measurement.

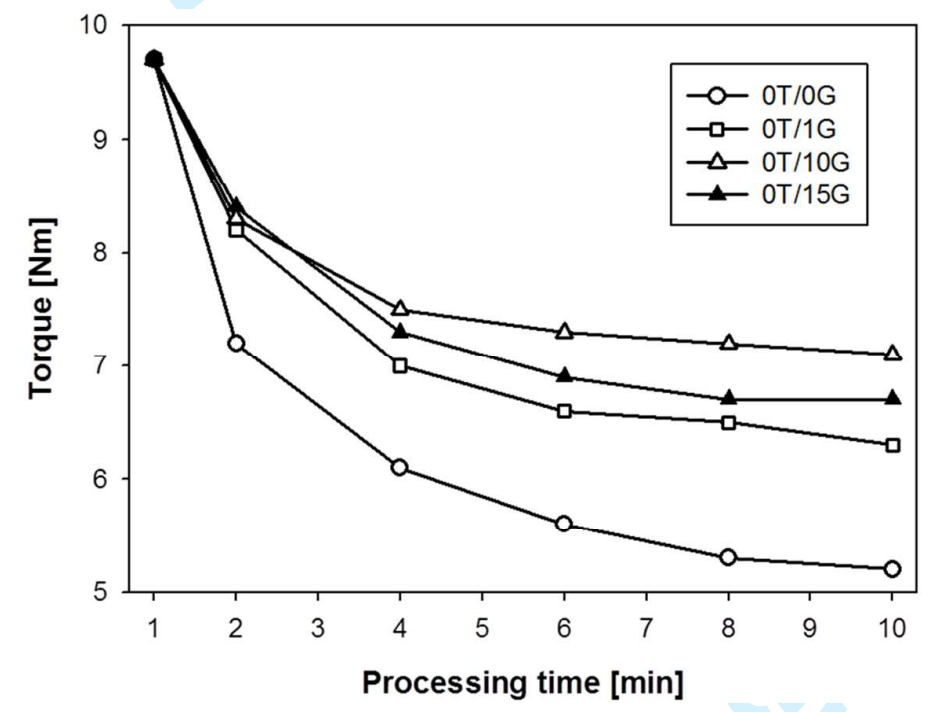

FIGURE 2: Torque during formation of PC-GnP nanocomposites at various processing stages. 


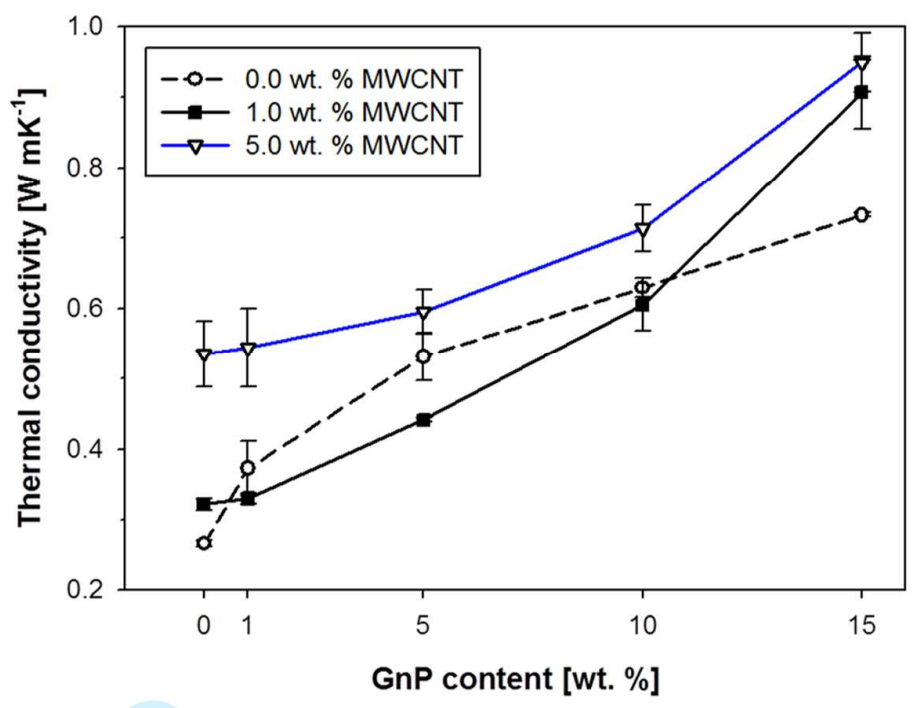

FIGURE 3: Thermal conductivity of PC-MWCNT/GnP hybrid nanocomposites.

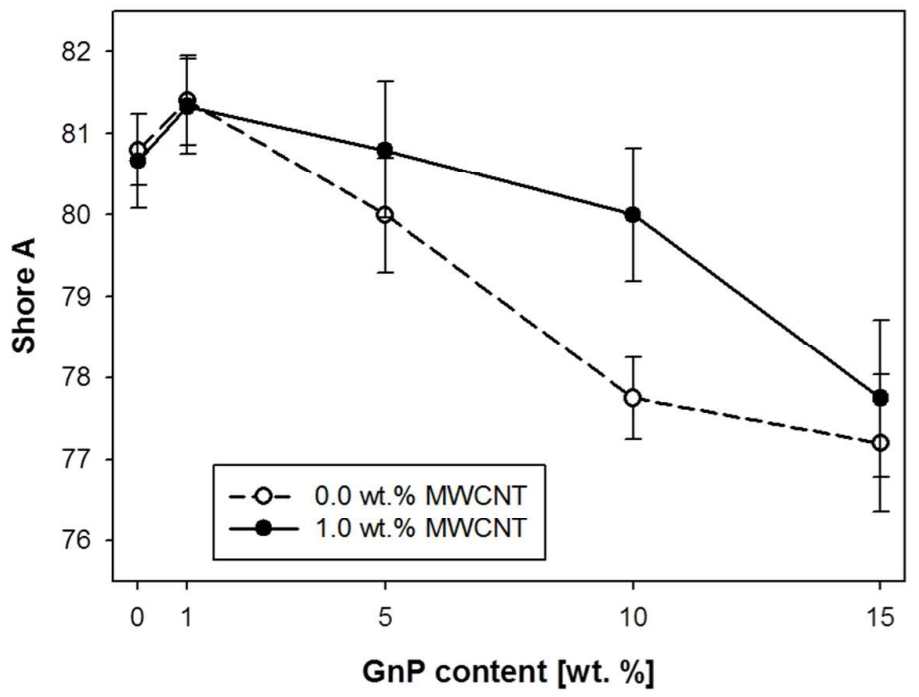

FIGURE 4: Shore A hardness of selected PC-MWCNT/GnP hybrid nanocomposites. 


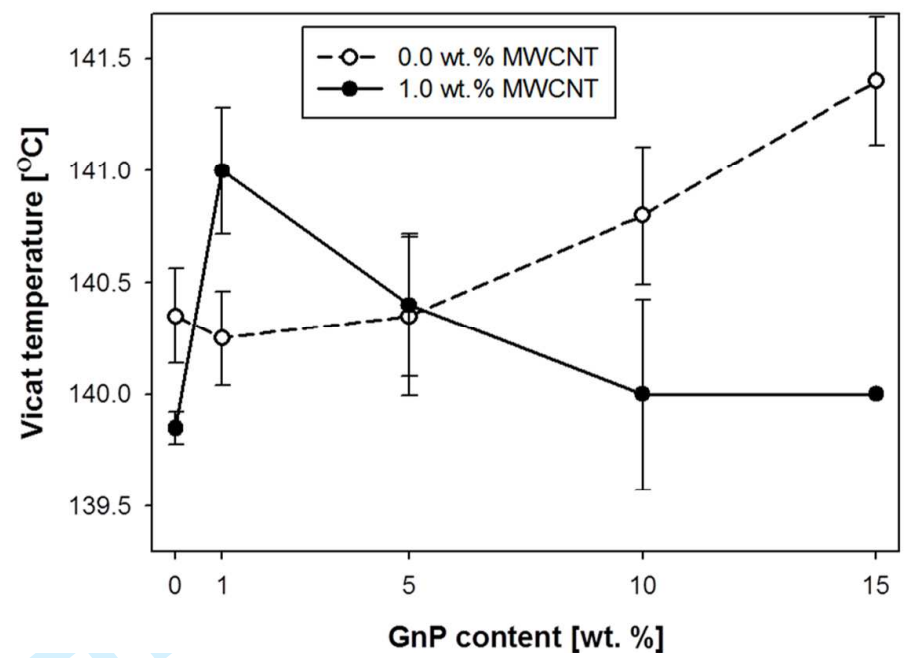

FIGURE 5: Vicat softening temperature of selected PC-MWCNT/GnP hybrid nanocomposites.

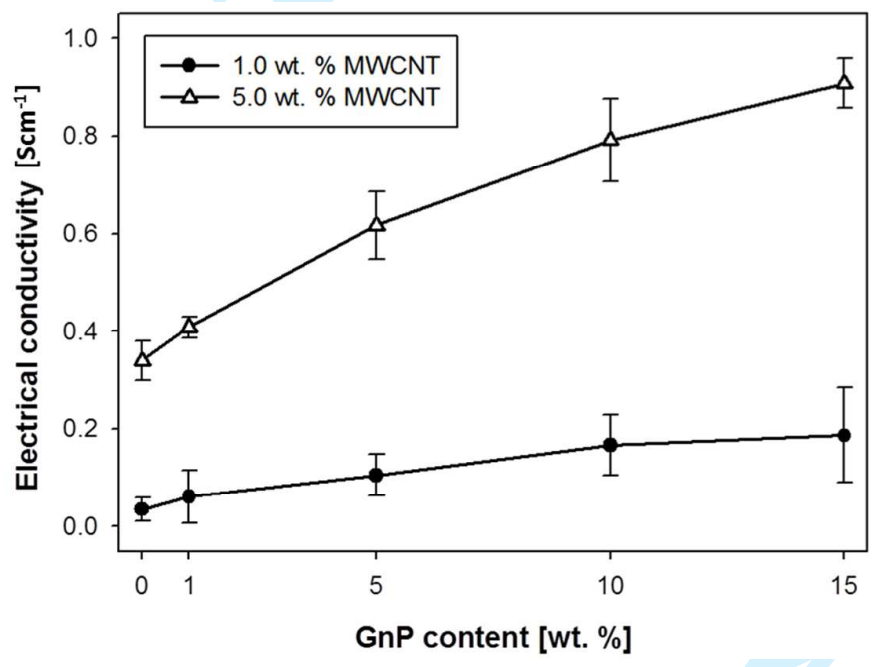

FIGURE 6: Electrical conductivity of selected PC-MWCNT/GnP hybrid nanocomposites. 
Table 1: Samples codification and nanofillers content in prepared PC-MWCNT/GnP hybrid nanocomposites.

\begin{tabular}{|c|c|c|}
\hline \multirow{2}{*}{ Sample code } & \multicolumn{2}{|c|}{ Content } \\
\hline & MWCNT & $G n P$ \\
\hline OT/OG & 0.0 wt. $\%$ & 0.0 wt. \% \\
\hline $0 \mathrm{~T} / 1 \mathrm{G}$ & 0.0 wt. $\%$ & 1.0 wt. $\%$ \\
\hline 0T/5G & 0.0 wt. \% & 5.0 wt. \% \\
\hline 0T/10G & 0.0 wt. $\%$ & 10.0 wt. $\%$ \\
\hline $0 T / 15 G$ & 0.0 wt. $\%$ & 15.0 wt. $\%$ \\
\hline $1 T / 0 G$ & 1.0 wt. $\%$ & 0.0 wt. $\%$ \\
\hline $1 T / 1 G$ & 1.0 wt. \% & 1.0 wt. \% \\
\hline $1 T / 5 G$ & 1.0 wt. \% & 5.0 wt. $\%$ \\
\hline $1 \mathrm{~T} / 10 \mathrm{G}$ & 1.0 wt. $\%$ & 10.0 wt. $\%$ \\
\hline 1T/15G & 1.0 wt. $\%$ & 15.0 wt. $\%$ \\
\hline $5 T / 0 G$ & 5.0 wt. \% & 0.0 wt. $\%$ \\
\hline $5 T / 1 G$ & 5.0 wt. $\%$ & 1.0 wt. $\%$ \\
\hline $5 T / 5 G$ & 5.0 wt. \% & 5.0 wt. \% \\
\hline $5 T / 10 G$ & 5.0 wt. \% & 10.0 wt. $\%$ \\
\hline $5 T / 15 G$ & 5.0 wt. \% & 15.0 wt. $\%$ \\
\hline
\end{tabular}

Table 2: Torque during formation of hybrid PC nanocomposites filled with various quantities of GnP and MWCNT.

\begin{tabular}{ccccc}
\hline Sample & \multicolumn{3}{c}{ Torque } & \\
& $4 \mathrm{~min}$ & $6 \mathrm{~min}$ & $8 \mathrm{~min}$ & $10 \mathrm{~min}$ \\
\hline $\mathbf{1 T / 0 G}$ & $6.5 \mathrm{Nm}$ & $6.3 \mathrm{Nm}$ & $6.0 \mathrm{Nm}$ & $6.0 \mathrm{Nm}$ \\
$\mathbf{1 T / 1 G}$ & $7.5 \mathrm{Nm}$ & $7.3 \mathrm{Nm}$ & $7.0 \mathrm{Nm}$ & $6.8 \mathrm{Nm}$ \\
$\mathbf{1 T / 5 G}$ & $8.6 \mathrm{Nm}$ & $7.8 \mathrm{Nm}$ & $7.5 \mathrm{Nm}$ & $7.4 \mathrm{Nm}$ \\
$\mathbf{1 T / 1 0 G}$ & $9.8 \mathrm{Nm}$ & $8.8 \mathrm{Nm}$ & $7.8 \mathrm{Nm}$ & $7.5 \mathrm{Nm}$ \\
$\mathbf{1 T / 1 5 G}$ & $9.5 \mathrm{Nm}$ & $8.5 \mathrm{Nm}$ & $7.7 \mathrm{Nm}$ & $7.4 \mathrm{Nm}$ \\
$\mathbf{5 T / 0 G}$ & $9.9 \mathrm{Nm}$ & $8.4 \mathrm{Nm}$ & $8.2 \mathrm{Nm}$ & $7.8 \mathrm{Nm}$ \\
$\mathbf{5 T / 1 G}$ & $10.9 \mathrm{Nm}$ & $9.5 \mathrm{Nm}$ & $8.6 \mathrm{Nm}$ & $7.9 \mathrm{Nm}$ \\
$\mathbf{5 T / 5 G}$ & $11.1 \mathrm{Nm}$ & $9.7 \mathrm{Nm}$ & $8.7 \mathrm{Nm}$ & $8.0 \mathrm{Nm}$ \\
$\mathbf{5 T / 1 0 G}$ & $11.2 \mathrm{Nm}$ & $9.9 \mathrm{Nm}$ & $8.7 \mathrm{Nm}$ & $8.2 \mathrm{Nm}$ \\
$\mathbf{5 T / 1 5 G}$ & $11.4 \mathrm{Nm}$ & $10.1 \mathrm{Nm}$ & $9.1 \mathrm{Nm}$ & $8.6 \mathrm{Nm}$ \\
\hline
\end{tabular}


Table 3: Thermal effusivity of PC-MWCNT/GnP nanocomposites measured at $26.1{ }^{\circ} \mathrm{C}( \pm 0.5)$.

\begin{tabular}{cc}
\hline Sample code & Effusivity $\left[\mathrm{Ws}^{1 / 2} \mathrm{~m}^{-2} \mathrm{~K}^{-1}\right]$ \\
\hline 0T/0G & $610.57( \pm 5.77)$ \\
0T/1G & $729.26( \pm 42.01)$ \\
0T/5G & $860.00( \pm 36.02)$ \\
0T/10G & $990.22( \pm 13.57)$ \\
0T/15G & $1087.50( \pm 2.93)$ \\
1T/0G & $673.87( \pm 9.73)$ \\
1T/1G & $682.82( \pm 8.93)$ \\
1T/5G & $801.67( \pm 33.17)$ \\
1T/10G & $966.96( \pm 37.64)$ \\
1T/15G & $1252.13( \pm 50.46)$ \\
$\mathbf{5 T / 0 G}$ & $906.79( \pm 78.26)$ \\
$\mathbf{5 T / 1 G}$ & $935.56( \pm 56.77)$ \\
$\mathbf{5 T / 5 G}$ & $957.57( \pm 31.22)$ \\
$\mathbf{5 T / 1 0 G}$ & $1069.70( \pm 31.46)$ \\
$\mathbf{5 T / 1 5 G}$ & $1275.19( \pm 35.36)$ \\
\hline
\end{tabular}

Table 4: Modulus of elasticity in compression determined from Shore A hardness.

\begin{tabular}{cc}
\hline Sample code & Modulus of Elasticity $[\mathrm{MPa}]$ \\
\hline $\mathbf{0 T} / \mathbf{0 G}$ & $12.89( \pm 0.70)$ \\
$\mathbf{0 T / 1 G}$ & $13.23( \pm 0.71)$ \\
$\mathbf{0 T} / \mathbf{5 G}$ & $12.46( \pm 0.67)$ \\
$\mathbf{0 T} / \mathbf{1 0 G}$ & $11.40( \pm 0.62)$ \\
$\mathbf{0 T} / \mathbf{1 5 G}$ & $11.17( \pm 0.60)$ \\
$\mathbf{1 T} / \mathbf{0 G}$ & $12.81( \pm 0.69)$ \\
$\mathbf{1 T} / \mathbf{1 G}$ & $13.19( \pm 0.71)$ \\
$\mathbf{1 T} / \mathbf{5 G}$ & $12.89( \pm 0.70)$ \\
$\mathbf{1 T} / \mathbf{1 0 G}$ & $12.46( \pm 0.67)$ \\
$\mathbf{1 T} / \mathbf{1 5 G}$ & $11.40( \pm 0.62)$ \\
\hline
\end{tabular}

Table 5: Electrical conductivity of selected PC-MWCNT/GnP nanocomposites.

\begin{tabular}{cc}
\hline Sample code & Electrical conductivity $\left[\mathrm{Scm}^{-1}\right]$ \\
\hline OT/0G & $1.00 \mathrm{E}-14( \pm 4.84 \mathrm{E}-14)$
\end{tabular}




$\begin{array}{ll}\text { 0T/1G } & 1.04 \mathrm{E}-10( \pm 2.38 \mathrm{E}-10) \\ \mathbf{\text { OT/5G }} & 7.59 \mathrm{E}-08( \pm 1.79 \mathrm{E}-06) \\ \mathbf{\text { OT/10G }} & 2.53 \mathrm{E}-05( \pm 2.85 \mathrm{E}-05) \\ \text { 0T/15G } & 5.60 \mathrm{E}-04( \pm 8.84 \mathrm{E}-04)\end{array}$

John Wiley \& Sons, Inc. 